\title{
Seguimos teniendo esperanza
}

\author{
Aquiles Montoya ${ }^{1}$
}

\section{Resumen}

En este artículo, el autor presenta algunos aspectos sobre la problemática nacional y ciertas ideas sobre sus causas, así como los límites y las posibilidades que existen de cara a la solución de las mismas. Asimismo expone algunas propuestas de modernización del aparato estatal, de cara a reducir el déficit fiscal, y, para finalizar con algo de esperanza, hace referencia a la alternativa popular.

\section{Introducción}

Antes de adentramos en los contenidos de este artículo, queremos destacar la tendencia pendular en que están cayendo algunos bien intencionadoś estudiosos de las ciencias sociales, sin percatarse de que al actuar de esa manera, excusan al sistema de sus muchas responsabilidades en materia de atención a los males provocados por la exclusión social.

Hace algunos años, para enfrentar la problemática nacional se acudió a la privatización, al menos ese era el discurso, y se satanizó cualquier acción estatal. Profesionales bien intencionados demostraban, con gran elocuencia, que el Estado no tenía nada que hacer en actividades propias del sector privado. Ciertamente, una fracción de la burguesía se aprovechó de los procesos de privatización para incrementar sus fuentes de riqueza a costa de toda la sociedad, mientras que los problemas, como era lógico esperar, lejos de menguar, se han incrementado.

Ante esta situación aparecen profesionales con muy buenas intenciones, clamando por la municipalización o estatización, alegando que inclusive en Estados Unidos hay actividades financieras que son estatales, de transporte que son municipales, etc. Sin embargo, tal movimiento pendular únicamente encubre la responsabilidad del sistema, porque al responsabilizar al Estado o al mercado, de manera alterna, de los males sociales, no se quiere ver que la raíz de los problemas no se encuentra en la mayor o menor presencia del Estado o del mercado, sino en el sistema que genera la problemática social. De modo que no demos palos de tonto y mientras vivamos en el sistema capitalista, con más o con menos mercado, con más o con menos Estado, los problemas sociales persistirán. Por eso,

1. Catedrático del Departamento de Economía de la Universidad Centroamericana “José Simeón Cañas". 
precisamente, es que se requiere encontrar una alternativa que, al mismo tiempo que enfrente la problemática social, vaya generando las bases para cambiar el sistema. Pues bien, de eso trata este artículo. Es importante decirlo expresamente a fin de enfrentar todas esas hipótesis derrotistas, carentes de esperanza y propias de quienes sólo tienen el cerebro para acumular saberes, pero no para pensar y mucho menos para proponer algo nuevo. Y me refiero explícitamente a aquellos que en el pasado les parecía una altemativa: la vía socialista, y no a ese otro grupo de "estudiados" a quienes lo único que les interesa es ganar mucho dinero para tener cosas. De quienes creen que ahora el "Pienso luego existo", ha sido reemplazado por: tengo luego existo, no amerita ocuparse.

\section{Seguimos sin aprender de la historia}

Existe una clara tendencia, o si se prefiere, una muy mala costumbre de no aprender de la historia. Somos muy dados a olvidar lo desagradable. En nuestra memoria colectiva se guardan tan sólo aquellos instantes de deliciosa fantasía; un buen ejemplo es la siempre recordada clasificación de nuestra selección al mundial de fútbol, en México 70 , y la terrible injusticia que acompañó a este suceso fenomenal, como fue la destitución de Goyo Bundio como entrenador, luego de haber conseguido el pase al mundial.

Y como no nos agrada el aprender de nuestros errores y la historia la olvidamos en todos aquellos pasajes trágicos, aunque nos pudieran aportar grandes enseñanzas, llegamos a sostener, e inclusive a creer, que "todo tiempo pasado fue mejor", ya se trate del fútbol, de nuestros amores, de nuestros empleos, o de las acciones del gobiemo. Se ha llegado al extremo de creer que con Martínez, el general teósofo, ya no estaríamos sufriendo de "tanta delincuencia".

Por esta forma de ser, tan nuestra, es que hemos aprendido muy poco de las causas y de los efectos de la guerra que sufrimos durante más de una década; esa poca inteligente decisión del "Perdón y olvido" nos retrata de cuerpo entero. Necesario sería que desde la escuela primaria se les enseñara a los niños NO SÓLO LOS MALES DE LA GUERRA, que ciertamente son muchos, sino también el por qué se llegó a tales extremos de violencia. De igual manera sería necesario y conveniente explicar a los educandos que las causas del conflicto no se han superado y que si se detuvo la guerra, fue porque se comprendió que ésta generaba males mayores que los que se buscaban resolver y que, en consecuencia, era preciso trabajar a fin de erradicar aquellos factores o causas que motivan a los pueblos a las salidas violentas.

Es claro que una actitud como la anterior exige de mucha honestidad para reconocer no sólo los errores ajenos sino también los propios, para poder ser objetivos e imparciales. No se trata de responsabilizar a unos o a otros. No es un problema que puede ser tratado ideológicamente, pero debe de ser tratado a fin de arrancarle a la guerra cualquier rasgo de romanticismo, que todavía persiste en más de alguno, por no atreverse a reconocer los males de esa actividad cruel, sanguinaria y deshumanizante, sin ningún tipo de excepciones. La vida, como valor supremo, debe servirnos como principio clave para valorar, enjuiciar y optar por una u otra altemativa, ante la búsqueda de vida y de mejor vida para las mayorías populares.

No nos gusta ser honestos con nosotros mismos, por eso siempre andamos a la búsqueda de chivos expiatorios. Así, como ante la desaparición del bloque socialista, resulta muy forzado y poco convincente culpar a los comunistas de nuestros males; nos conformamos con culpar al "directo", a las maras, a las guerras entre narcotraficantes, etc., pero nunca profundizamos en las causas reales de nuestros problemas. La desgracia de esta actitud es que corremos el peligro de heredar a nuestros hijos otro conflicto sangriento, aunque asuma modalidades y características diferentes; con la cantidad de armas que se comercian en el país, un estallido social sería una cosa espantosa. Sólo imaginemos qué podría esperar una sociedad en la que se asesina a las personas por simples problemas de tránsito, por una mala mirada o por una supuesta "puteada", ya que nunca llegó a escucharse, sino que simplemente así fue interpretada la vocalización que hizo otro conductor. Esta es la sociedad que estamos construyendo de cara al nuevo milenio, con el auxilio del mercado y gracias a la globalización cultural. El negocio de las armas también deja muchas ganancias y la televisión nos muestra que no se puede vivir sin ellas, en una sociedad civilizada como las de hoy en día. Los diputados militares, hijos de la guerra, auspician leyes que amplían la demanda de armamento. La legítima defensa ha pasado a convertirse en la ley del mejor armado. 


\section{Seguimos sin querer comprender la realidad esencial}

Para trabajar por y para que exista una mejor vida es de suma importancia, además de impregnarnos del pasado, comprender la realidad presente, y para tal propósito comenzamos la siguiente cita:

La realidad actual, dominada por la globalización del capital transnacional genera dos graves problemas a nivel mundial: la exclusión social y la destrucción medio ambiental, ambos exigen de análisis, de conocimiento y de propuestas novedosas, ya que dejados a la suerte del mercado tenderán a incrementarse, a agravarse, lo cual es un mal para las mayorías populares de El Salvador y del mundo ${ }^{2}$.

La problemática de la exclusión social ya se ha tratado bastante, al menos en lo que a sus efectos se refiere. Sin embargo, se trata de un fenómeno relativamente novedoso por dos aspectos: su magnitud y su permanencia. De allí que sea muy importante entender el porqué de la exclusión, esto es, conocer cuál es su causalidad y qué es lo que la hace permanente y cuantitativamente significativa. Así como también es importante y necesario conocer la problemática ambiental y las barreras que se presentan de cara a su preservación y recuperación.

Pero vayamos paso a paso y comencemos por exponer lo relativo a la exclusión social. El fenómeno de la exclusión social se refiere - como su nombre lo indica- a que muchísimas personas, miles de millones de personas: no tienen un trabajo remunerado, ni acceso a educación, ni a servicios de salud, ni a medicamentos, ni a viviendas dignas, ni a agua potable, ni a energía, ni a ningún tipo de seguridad social tan requerida en la vejez, etc. etc. Y para aquellos que pueden ofrecer algún producto o servicio para la venta, el mercado les reconoce precios tan bajos que les es imposible la reproducción material de la vida utilizando el mercado como mecanismo de distribución y asignación de recursos. Incluso se les puede incorporar al mercado laboral con salarios miserables y siguen siendo excluidos, ya que no pueden comprar los bie-

nes y servicios que el sistema ofrece y que ellos necesitan. Se habla de exclusión social porque las personas están siendo excluidas de los beneficios del sistema, de las ventajas del mercado, de la libre empresa, de la libre iniciativa, aunque no lo estén de sus males o desventajas, lo cual viene a complicar aún más las cosas.

Lo grave de esta situación es que está ocurriendo pese al crecimiento de la economía mundial, lo cual ha estado sucediendo durante la presente década. No se trata, pues, del efecto coyuntural de una crisis, sino de la nueva modalidad de funcionamiento del sistema capitalista en su fase de globalización. El sistema, al ser liderado por las empresas transnacionales, exige para su mejor funcionamiento de eficiencia y eficacia, aunque con ello genere exclusión social. No es posible, ni necesario para los intereses de las transnacionales, que todos los habitantes del planeta sean incluidos dentro de la realidad capitalista globalizada, aunque tal hecho pudiera significar, en determinadas circunstancias, el condenarlos a muerte. Esto, si bien es terrible no es sorprendente, si recordamos el carácter necrófilo de la producción capitalista y su tendencia a que predomine el trabajo objetivado, esto es, la parte muerta del capital sobre el trabajo vivo.

La producción capitalista se caracteriza por su tendencia incesante a incrementar la productivi-

2. Urfano Calles, "Los cambios en El Salvador", Revista ECA, mayo-junio, 1999. 
dad; ésta es una condición necesaria para su existencia, por ello recurre a elevar constantemente la composición orgánica del capital. Dicho en otras palabras, los procesos de producción capitalistas se caracterizan por presentar una relación capital/ trabajo cada vez mayor. $O$, si se prefiere, lo mismo desde otra perspectiva: para crear un nuevo puesto de trabajo se requiere cada vez de una mayor masa de capital, en promedio. $\mathrm{Y}$ si a esto le añadimos que se requiere, por parte de los trabajadores, cada vez de mayores niveles de capacitación, se comienza a entender el porqué la globalización tiende a ser excluyente. El capital transnacionalizado no sólo demanda menos trabajadores por cada nuevo millón de dólares invertido, sino que va allí, adonde encuentra trabajadores que perciban un menor salario promedio anual, incluidas las prestaciones sociales que tienden a eliminarse, y con las habilidades y capacidades exigidas por la nuevas tecnologías. Siendo esto así, no resulta extraño que el desempleo estructural se esté haciendo presente, aun en los países desarrollados, como la Unión Europea y Japón, donde para paliar un poco la situación de desempleo y sus consecuencias, se está recortando la duración de la jomada de trabajo, lo mismo que las remuneraciones, con lo cual existe el riesgo - y peor aún, la tendencia- de precarización de las condiciones de vida, inclusive, de los trabajadores del primer mundo.

A partir del razonamiento anterior se podría argumentar que la exclusión social no existiría si la fuerza de trabajo se capacitara en la forma debida y suficiente y si el ritmo de crecimiento de la economía fuera tal, que pudiera absorber a los nuevos contingentes de trabajadores que, año con año, se incorporan al mercado de trabajo, en busca de un empleo remunerado - tal como parece presentarse en Estados Unidos actualmente, aunque tal situación seguramente no podrá perdurar por mucho tiempo más, como ya dejó de serlo en Europa y Japón-.
No obstante, esa ha sido la tendencia que durante muchos años ha prevalecido en el mundo desarrollado, para desgracia de la realidad ambiental. No obstante, ahora hemos llegado a un punto en el cual parece claro que es imposible que el planeta pueda resistir, por mucho tiempo más, un crecimiento económico tal que sea capaz de absorber a los nuevos contingentes de trabajadores que, año con año, buscan incorporarse al mercado laboral. En consecuencia, a los límites propios del sistema, como la lendencia recurrente a la caída de la tasa de ganancia, por ejemplo, se añade el límite ambiental.

Pero el impacto medioambiental no sólo se origina en la producción industrial capitalista $y$ en la modalidad consumista que exige aquella para su reproducción en escala ampliada, sino que también se origina en la pobreza y el subdesarrollo propiciado y, o generado en las regiones periféricas, donde los modelos extractivistas de producción han respondido más a los intereses económicos del centro, que a la preservación de los ecosistemas y a las exigencias de los pueblos por salir de su pobreza.

En Centroamérica hemos creado todas las condiciones favorables para la maximización de desastres naturales y sus secuelas sociales ${ }^{3}$.

Supongamos, por un momento, que el ritmo de crecimiento económico y el nivel de consumo de Estados Unidos se reproduzcan en el mundo entero. La respuesta es harto sabida: el efecto sería sencillamente desastroso en términos ambientales, aunque quién sabe por qué razón no se toma conciencia del mismo y seguimos con propuestas que parecen suponer todo lo contrario. Sólo imaginemos qué sería de El Salvador si cada familia tuviera un automóvil, lo cual si bien es un supuesto absurdo, nos permite comprender mejor la problemática de la cual nos ocupamos. Por otra parte, como el Tercer Mundo recicla los deshechos del

3. W. Campos y R. Pasos, "Después de la tempestad no viene la calma", revista Hombres de Maíz, marzo-abril, 1999, p. 44. 
primero, la inundación de autos usados que ya padecemos en el país es terrible y lo que para un ministro se presentaba como indicador de bonanza, de mejoría social, la duplicación de la cantidad de vehículos que actualmente circulan por nuestras calles atestadas, sería el mayor desastre artificial generado por una sociedad humana determinada. Y no faltará quien diga que esa es una razón suficiente para que la mayoría de la población siga viviendo con bajos ingresos, ya que, de lo contrario, peligrarían las condiciones de vida para todos. Y aunque lo anterior parezca tan sólo humor negro, la racionalidad excluyente de la globalización "protege el globo", propiciando acciones y formas de vida dentro de ese esquema de pensamiento, tan propio del editorialista de $E l$ Diario de Hoy.

Es importante entender también que, dadas las técnicas actuales, la demanda relativa de fuerza de trabajo tiende a ser cada vez más baja; por otro lado, ninguna empresa estará dispuesta a disminuir sus beneficios a fin de emplear a más personas innecesarias para el buen funcionamiento empresarial, aunque ello repercuta en que la sociedad funcione muy mal. Ya veiamos el tipo de salidas que se implementan, como el emplear a más gente pero durante menos tiempo y con menor salario - con lo cual se amplía la masa de personas que ven deterioradas sus condiciones de vida- o bien, pagar salarios miserables por largas e intensas jornadas - lo cual es la práctica en los países periféricos-. Siendo esto así y conociendo que la tasa de crecimiento poblacional en los países pobres sigue siendo elevada, las posibilidades de que los pueblos pobres dejen de serlo, gracias a su incorporación al sistema, parece no tener ninguna posibilidad ni viabilidad.

Ahora bien, si a los capitalistas —de acuerdo con su racionalidad empresarial- nunca les ha importado la precariedad de la vida o, inclusive, la muerte de las personas, es lógico que tampoco les importe la muerte de otras formas de vida, consideradas inferiores, como lo demuestra el hecho de que cada año en el mundo desaparecen 40000 especies entre animales y vegetales. Y así como se aniquila la vida animal y vegetal de manera masiva, también se van preparando estas condiciones: contaminación del aire, el agua y la tierra; elevación de la temperatura ambiental y destrucción de la capa de ozono; lluvia ácida; deforestación —entre 10 y 17 millones de hectáreas de bosque desaparecen cada año- y alrededor de 6 millones de hectáreas de tierra cultivable desaparecen cada año por desertificación, etc. $Y$ como mencionamos, se van preparando las condiciones para dar el gran golpe, esto es, para aniquilar toda forma de vida, incluyendo la vida humana. Ésta podría llegar a ser: ¡La gran hazaña del ser humano en el siglo XXI!

En consecuencia, la economía mundial liderada por las empresas transnacionales y dejada a las fuerzas ciegas del mercado, podrá mantenerse un tiempo más, quién sabe con seguridad cuánto más, pero lo que si se sabe con seguridad es que será a costa de mayor exclusión social y mayor degradación ambiental. Ahora bien, para que ello no ocurra es preciso que hagamos algo, ¿pero qué? Ciertamente intentar proponer algunas ideas luego de haber mostrado los alcances de la problemática actual, donde la realidad mundial ofrece límites que resultan infranqueables, parece ser una tarea demasiado ambiciosa. Sin embargo, es preciso tener en cuenta algunas cosas: primero, no todo lo nacional está determinado por la realidad mundial, en consecuencia existe posibilidad de actuar. Así, por

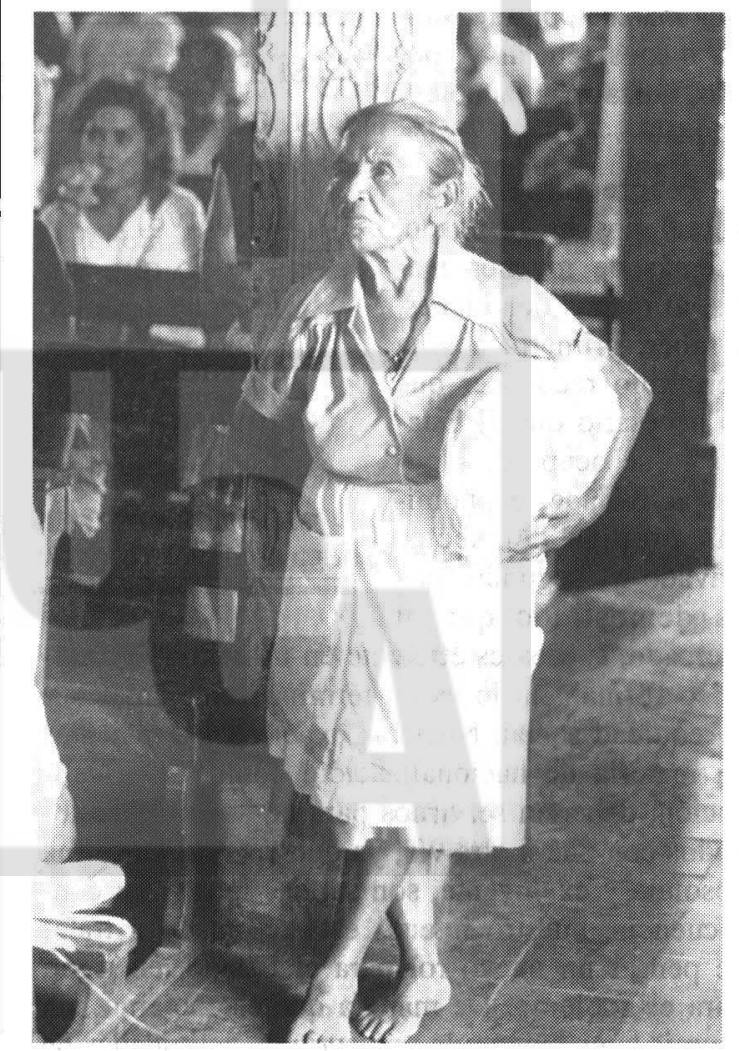


ejemplo, hay espacio de sobra para modemizar los aparatos gubernamentales; segundo, la exclusión misma abre espacios para el funcionamiento de actividades alternativas. Diferente sería que la globalización revistiera tendencias incluyentes, al punto de tender a abarcarlo todo, pero menos mal, no es así.

\section{Seguimos sin querer enfrentar los problemas}

Debería ser una obviedad que rechazar el mercado no significa estar a favor del gobierno, o que rechazar el mercado significa apoyar el estatismo. Pensar asi es propio de las mentes maniqueístas. Pero ocurre con frecuencia que cuando cuestionamos la viabilidad de avanzar en el camino de las soluciones a la problemática social mediante la actividad gubernamental, cuya eficacia ya se conoce y está comprobada, se cree que estamos a favor del mercado, pero si decimos que tampoco estamos por el mercado, entonces pareciera que la única posibilidad es que seamos anarquistas. $Y$ aunque el anarquismo cuenta con mucha racionalidad en sus principios, razón por la cual no me avergonzaría de serlo, nuestra idea marcha por otro rumbo menos radical $y$, por ello, quizá más factible y aceptable.

El predominio neoliberal nos ha brindado, además de muchos males, al menos dos bienes, a saber: primero, nos ha permitido reconocer que es necesario que el Estado no se ocupe de algunas actividades económicas propias del sector privado $y$, segundo, nos ha demostrado que el
... si a los capitalistas — de acuerdo con su racionalidad empresarial- nunca les ha importado la precariedad de la vida $o$, inclusive, la muerte de las personas, es lógico que tampoco les importe la muerte de otras formas de vida, consideradas inferiores, como lo demuestra el hecho de que cada año desaparecen en el mundo 40000 especies entre animales y vegetales. interes social, no evada la responsabilidad que le compete respecto de las mismas.

El gobiemo debería ser responsable, además de sus tradicionales funciones, de velar por la preservación y mejora ambiental, así como por la equidad social. Lo cual parece bastante obvio, en tanto que cualquier sociedad requiere de equidad para sus miembros, así como de la conservación del ambiente para poder existir en el tiempo, sin tener que sufrir desgarramientos sociales y ecológicos.

Sin embargo, parece no ser el momento más adecuado para hacer propuestas, en razón de que en el país estamos viviendo una etapa de superabundancia propositiva, como antes nunca se había visto, a la par que padeciendo de sectarismo social en materia de conocimiento y estudio de las mismas. Se publicitaron las propuesta de ANEP, de FUNDE, de ARENA y del FMLN, de FUSADES y la propuesta del para oficial Plan de Nación. Y la última, la de las "autopistas centroamericanas", con pretensiones de acabar con la pobreza en toda la región. Aparte del derroche de recursos humanos y materiales, algunas propuestas son carísimas, otras son meros "chotazos", pero ninguna de las propuestas parece enterarse de la existencia de las otras, pese a que han sido consecutivas. $Y$ tampoco han servido, siquiera, como temas para el debate social. De manera que el ambiente para las propuestas no parece ser el óptimo, pese a que ahora se rechaza la crítica o la denuncia, si no va acompañada de su respectiva propuesta, lo cual parece ser mercado, si bien es eficiente en un sentido económico formal, no lo es en términos ambientales y de equidad social. Nuestras experiencias recientes en materia de nacionalización, como de privatización, deberían servimos para no seguir obsesionados con una u otra vía, ya que las dos, en forma absoluta y excluyente, son salidas falsas. En consecuencia, nuestro intento está orientado a tratar de pensar un nuevo rol para el Estado, en rigor, para el gobierno. De manera que el gobierno, sin asumir la ejecución de una serie de actividades de más por razones de moda que de interés social real.

Adicionalmente, el realizar planteamientos propositivos, además de ser difícil es frustrante para quien lo haga con fines meritorios, ya que no sólo se ignoran sino que se desprecian. Pero, con todo, hay ideas que se llegan a constituir en ideas fuerza y son aceptadas y asumidas por los más diversos sectores. Esto ocurre generalmente cuando éstas son redescubiertas por personajes extranjeros o, cuando menos, por apellidos de difícil pronuncia- 
ción, lo cual les da credibilidad ante nuestros malinchistas conciudadanos. Pero bien, cómo penetran las ideas nuevas no parece ser lo importante, cuando lo que se busca es tan sólo hacer algo a favor de las mayorías populares.

En línea con las propuestas y las ideas fuerzas, observamos, como ejemplo, que en la actualidad son muy raras las personas que no estén a favor de la participación de la ciudadanía en una amplia gama de actividades sociales, cuando en el pasado las decisiones y proposiciones eran patrimonio casi exclusivo de las vanguardias, fueran éstas de derecha o de izquierda, "iluminados" hay de este y del otro lado.

Participación ciudadana que está generando beneficios adicionales, tal es el hecho de poner en evidencia la debilidad de la democracia representativa, como lo atestigua la Asamblea Legislativa, cuando exige la participación ciudadana en la toma de decisiones políticas que son de su incumbencia, pues los diputados son los representantes del pueblo. Este hecho debería servir como estímulo a la vieja y necesaria búsqueda de redimensionar el número de diputados integrantes de la Asamblea Legislativa. Es bastante evidente que nuestro Congreso está formado por un excesivo número de diputados respecto a las funciones que realiza. La Asamblea Legislativa, como otras muchas instancias gubernamentales en la actualidad, sirve preferentemente para que los políticos profesionales tengan un medio de vida. Por tal razón, y buscando hacerla eficiente, la Cámara Legislativa podría funcionar mejor con sólo $14 \mathrm{di}$ putados, simbólicamente, uno por departamento. Pero electos por votación nacional, de la misma forma en que se elige al presidente y vicepresidente de la república, luego se procede al reparto proporcional de las curules, según el número de votos obtenidos por cada partido político participante. De esta manera, se podrían buscar personas más capaces para que aspiren a las diputaciones - las cuales no son muy abundantes-, y lo mismo se podría hacer para los asesores. Actualmente es vergonzosa la incapacidad de unos y otros, al punto de que ni siquiera saben redactar. El Dr. José E. Silva, abogado, notario y ex docente universitario, les pregunta:
Ante esta redacción que atropella manifiestamente la gramática y concretamente la sintasix, preguntamos a los autores de esta curiosa reforma constitucional: ¿Hay acaso personas humanas que no sean seres humanos? ${ }^{4}$

Lo triste de este hecho es que si se equivocan en la redacción de las leyes, cómo no se van a equivocar en los contenidos jurídicos de las mismas, en las concepciones de las mismas, etc. $Y$ no se crea que la redacción de una ley es algo carente de importancia, al contrario, es muy seria, ya que puede entenderse de una manera totalmente distinta de aquello que se quiere expresar y, en consecuencia, cambiarse totalmente el fin, el objetivo, la calidad, el contenido, etc. de la misma.

En la actualidad, la producción legislativa ha sido, en términos de calidad, una de las más pobres en la historia salvadoreña, ya que es común o habitual que al poco tiempo de haberse emitido una ley, se solicite su reforma o que sea declarada inconstitucional, a causa de sus vicios o su ilegalidad. Pero no podría ser de otra manera, dada la enorme cantidad de incompetentes que integran la Asamblea. Para resolver este problema, reiteramos, es necesario reducir el número de diputados que la integran y aumentar el número y la calidad de sus asesores. De modo que el ser diputado sea motivo de orgullo y admiración, y no un lugar donde se puede cobrar un sueldo elevado sin hacer poco más que nada. Además de lo anterior, también hay otros muchos vicios, de sobra conocidos, que tan sólo servirían para abonar nuestra tesis acerca de la necesidad de comprimir la Asamblea, además de aducir razones de tipo presupuestario. No tiene ningún sentido pagar mayores impuestos para que sean derrochados; son más de 100 millones de colones los que insume el Órgano Legislativo, y tan poco y de tan mala calidad lo que produce.

Por otra parte, para que florezca la participación ciudadana, que comienza a crecer y desarrollarse en nuestro medio, es preciso sistematizarla, ya que así se institucionalizaría y no dependería de la conveniencia, o voluntad circunstancial de los políticos de turno, la participación que se realice en una u otra actividad. Y la mejor forma de avan-

4. La reforma dice: "Asimismo reconoce como persona humana a todo ser humano desde el instante de la concepción". Una reforma constitucional contra la gramática, P.G. (23 de junio de 1999). 
zar en esta línea es profundizando la autonomía municipal, para lo cual los municipios necesitan de recursos. Si se van a descentralizar las funciones del gobierno, lógico resulta que se descentralicen también los recursos, al fin y al cabo se trata de fondos públicos que deberían ser manejados por quienes realizan los servicios o las inversiones públicas. Pero mucho cuidado con la descentralización, no se trata de sustituir un estatismo por otro, de pasar del estatismo nacional al estatismo municipal, ya que con ello se estarian multiplicando las oportunidades para la corrupción. Los gobiemos deben de cumplir funciones de control, de regulación, de contratación, de supervisión, etc., ya sea a nivel nacional o municipal, pero muy pocas de ejecución o prestación de servicios. Dicen que "en arca abierta hasta el justo peca", ¿qué ocurrirá cuando no son justos?

Al movernos a nivel municipal y departamental, algunos funcionarios aparecen como especies raras, como fenómenos de otra época, como fósiles vivientes, cuya presencia ya no tiene ninguna razón de ser y lo único que hacen es consumir parte de los recursos escasos de que dispone el gobierno para realizar una cantidad de funciones urgentes, necesarias e indispensables, tal es el caso de los gobernadores departamentales, auténticas piezas de museo, que a fuerza de no hacer nada, han pasado desapercibidos y la evolución social no ha podido con ellos. Sin embargo, no existe razón ni excusa para que no sean eliminados de una vez y para siempre. ¿Cómo se puede aceptar que se incrementen los impuestos si antes no se recortan los gastos innecesarios?

En línea con la austeridad y el uso racional de los recursos públicos, esto es, de nuestros impuestos, no existe razón, argumento, ni necesidad alguna para mantener por un año más la considerable suma del presupuesto nacional que se destina al Ministerio de Defensa. Si se pretende justificar el mismo con la asignación ocasional de funciones de seguridad pública, mejor sería que sus efectivos se trasladaran al Ministerio de Seguridad Pública y trabajaran todo el año, como lo hacen los policías. Si se quiere realmente modernizar el Estado, si se quiere reducir el gasto de funcionamiento, es necesario prescindir del Ministerio de Defensa. Que el gobierno invierta hoy unos cuantos cientos de millones de colones en indemnizar o pensionar a los militares y habremos acabado de una vez y para siempre con tal sangría social. Costa Rica ha logrado sobrevivir sin ejército, por qué no habríamos de poder hacerlo nosotros también, sobre todo si los recursos que ellos consumen se podrían utilizar en distintos servicios y fines sociales, como educación, salud, salubridad, ambientalismo, reforestación, etc. ¿Cómo podemos aceptar que se graven con impuestos los alimentos y las medicinas, para poder pagarle a tanto militar inútil $e$ innecesario? Porque las funciones constitucionales de defender la soberanía nacional y la integridad del territorio no son necesidades y ni las cumplen. De lo contrario, cómo se explica la entrega de parte de nuestro limitado y escaso territorio nacional a la vecina, voraz y rapaz hermana república de Honduras, sin que las Fuerzas Armandas hayan devengado los sueldos y salarios que durante más de un siglo han cobrado. En cuanto a la soberanía nacional, ¿quién sabe qué entenderán por la misma en esta época de globalización y profundización de la dependencia? Lo que sí resulta claro es que los militares no han hecho ni hacen nada para preservarla. Y aunque parezca increíble, a la defensa se le destinaron, sólo en este año, nada menos que la cantidad de 963 millones de colones.

Veámoslo desde otra perspectiva: ¿cómo es posible que vivamos angustiados por la delincuencia, que inversionistas extranjeros no se animen a venir al país por la inseguridad ciudadana, que nadie quiera invertir en el agro dado el peligro de ser secuestrado, asaltado o asesinado y tengamos una Policía Nacional Civil con recursos insuficientes, mientras el Ministerio de Defensa, que no nos presta ningún servicio, consume casi mil millones de colones anuales?

No es que estemos contra los militares, ellos están contra nosotros, ya que viven de nuestros impuestos y no prestan ningún servicio; pareciera que los mantenemos por temor y si ese fuera el caso, serían parte del problema porque si nos tienen chantajeados, no sólo no nos prestan ningún beneficio, sino que son nocivos para nuestra convivencia democrática.

Los casos citados son tan sólo ejemplos que ilustran la necesidad de modernizar el Estado salvadoreño, pero de modemizarlo en serio. Como esos hechos, existen muchísimos otros más sobre funcionarios y empleados, o mejor dicho de instituciones y cargos que deberían eliminarse, modificarse $y / 0$ adaptarse a las nuevas realidades. El gran problema es que así como nos costó pasar de la protesta a la propuesta, ahora resulta muy difícil 
pasar de la propuesta a la acción, a causa de los terribles entramados que constituyen los intereses económicos y políticos que, en la mayoría de ocasiones, casi inmovilizan a quienes poseen la potestad y la obligación de actuar.

Cuando se tienen problemas de déficit presupuestarios, como le ocurre actualmente al gobierno, es más conveniente buscar cómo reducir los gastos que tratar de incrementar los ingresos, sobre todo cuando se quiere hacer a costa de las medicinas y los alimentos de un pueblo pobre, enfermo y mmal alimentado. No es extraño que a los empresarios les parezcan adecuadas las medidas del nuevo gobierno, ya que ellos no resultan afectados por las mismas. ¿Dirian lo mismo si se hubiera establecido un impuesto al patrimonio? ¿O si se hubieran grabado más las ganancias? Ésta es una muestra más de que no tiene sentido hacerse ilusiones: los gobiernos de ARENA no tardan en demostrar su carácter impopular, $P O$ BRES LOS POBRES QUE SIGUEN VOTANDO POR ELLOS.

\section{Seguimos carentes de criterios y principios}

A'veces no se sabe cómo actuar, debido a que se presentan conflictos de intereses que llegan al punto de enturbiar la razón; entonces, para atacar los problemas se hace necesario tener una mente clara y para ello resulta de gran ayuda contar con ciertos criterios o principios que iluminen la realidad y le den sentido a nuestro accionar. Por ejemplo, el padre Ellacuría nos enseñó que el criterio para dilucidar si se debía apoyar o no una determinada acción o medida, era que la misma beneficiara o no a las mayorías populares; por esa razón la UCA apoyó la Transformación Agraria de Molina, así como otras muchas medidas y acciones a lo largo de su historia, así como estuvo, y a veces aún está, en contra de otras. Desde esta perspectiva es obvio que no se puede estar a favor del incremento de los impuestos a los alimentos y a las medicinas. Quien por una u otra razón intente justificar tales medidas, evidencia su poca claridad en materia de principios. No se puede estar a favor de los pobres y actuar en contra de los mismos, o justificar aquellas medidas que les perjudican.

Entrando en materia de conflictos, un problema que enfrenta la humanidad está referido al conflicto de intereses que se presenta en materia ambiental y de salud de las personas, entre el interés privado y el interés social. Antes de proseguir presentaremos algunos ejemplos que ilustran lo que se ha expuesto: se siguen introduciendo, en el país, procesos, productos y materias primas que son tóxicos, contaminantes o no biodegradables, los mismos que se han prohibido en los países desarrollados, lugares de donde provienen. A nuestro país llegan porque no contamos con una legislación adecuada, o bien porque el gobiemo no aplica la legislación existente. La empresa privada, ciertamente, busca su interés; sin embargo, al hacerlo afecta el interés social.

El hecho ideal sería que la empresa privada actuara sobre la base del respeto hacia el interés social, y en caso de que no lo hiciera, que cargara con los costos de su proceder equivocado. Pero para que esto sea realidad se necesita, cuando menos, de una legislación ad hoc y, en su defecto, de responsabilidad social por parte de la ciudadanía.

¿Será mucho pedirle a los empresarios que actúen con responsabilidad social? Por ejemplo, aquellos que venden productos envasados que contienen cloroflurocarbonos (CFC) que destruyen la capa de ozono, ¿estarían dispuestos a dejar de hacerlo? O se escudarán irresponsablemente tras el mercado, argumentando de que no tienen culpa de que las personas se los compren, pero que en el momento en que éstas dejen de demandarlos ya no los venderán. ¿Pero qué es esto? ¡Esa es la lógica de los narcotraficantes! El día que ya nadie les compre drogas dejarán de venderlas porque ya no sería negocio, pero mientras tanto que viva el comercio. El comerciante dirá que él busca satisfacer a sus clientes, lo mismo dirá el narcotraficante. Con tales argumentos no llegamos a ninguna parte.

Parece claro, entonces, que se requiere de responsabilidad social. Que si bien es lícito hacer ne- 
gocio, buscar las ganancias, existen o deben existir ciertos principios de carácter general que regulen nuestras acciones. $Y$ así como no se considera legítimo hacer dinero comerciando con drogas, de igual manera no puede serlo el hecho de vender productos nocivos para la salud de las personas, de los animales o de las plantas o que destruyan el medio ambiente.

La responsabilidad social debería ser regulada por nuestra legislación, y quienes resultaran responsables de haber perjudicado la salud de las personas o dañado el medio ambiente - debido a la venta de sus productos-, por lo menos deberían ser juzgados judicialmente, y si se les encontrase culpables, que respondan judicial $y$ económicamente por la daños ocasionados. Algunos ejemplos serían quienes venden gasolina con plomo, productos de o con asbesto, insecticidas quími$\cos$ nocivos a las personas, productos con CFC, cigarrillos, productos alcohólicos, etc. Citamos estos ejemplos porque sus efectos negativos son de sobra conocidos, de manera que los empresarios han actuado con conocimiento de causa, o sea, a sabiendas del daño que causan. Y esa conducta puede calificarse de irresponsable socialmente, cuando no judicialmente delictiva. A fin de actuar, el gobiemo debería de atenerse al siguiente principio: cuando el interés privado se satisfaga a costa del interés social, deberá de penalizarse al responsable y prohibirse su actividad.

Pero como los argumentos o justificantes éticos pudieran no resultar todo lo convincentes que se esperaría, habrá que hacer las argumentaciones en términos objetivos, de manera que no haya lugar a la evasión mediante justificaciones de carácter subjetivo. Es claro que si se causan daños al medio ambiente o a la salud de las personas, ello se traduce en perjuicios económicos para la sociedad como un todo, ya que más tarde o más temprano se tendrán que destinar parte de los recursos escasos a la atención de los daños ocasionados a las personas, los animales o las plantas, por las actividades de los empresarios a los que hemos hecho referencia con anterioridad.

Lo anterior nos está planteando precisamente otro conflicto, que es el de la rentabilidad social versus la rentabilidad privada. Mientras los particulares han realizado actividades rentables, positivamente rentables para ellos, esas mismas actividades se han traducido para la sociedad en una rentabilidad negativa, ya que la sociedad ha tenido que gastar recursos para tratar a las personas que se enfermaron a causa del consumo de los productos nocivos. O bien, otro caso sería la atención que se brindara a los damnificados por una inundación, secundaria a la deforestación realizada por las empresas madereras o por los constructores de viviendas, o bien por los agricultores que cultivan tierras deforestadas y no aptas para cultivos anuales.

En el balance nacional, algunos particulares han ganado con sus actividades comerciales; sin embargo, a consecuencia de sus actividades se registran rubros negativos, que son todos aquellos gastos en que no se hubiera incurrido si no se hubiesen realizado actividades cuyos impactos son negativos.

Ciertamente, no resulta fácil conciliar la rentabilidad social con la rentabilidad privada, como tampoco resulta fácil armonizar la economía con la ecología; pero ese no es el punto. Lo importante es que si deseamos seguir habitando esta región del mundo, e inclusive el mundo mismo, será necesario tratar de hacerlo y, si fuera imposible, se tendrá que sacrificar el interés privado, mas nunca el social. Nadie dijo que era fácil, como tampoco que sólo hay que hacer las cosas fáciles. Precisamente cuando las actividades son difíciles es que se reconoce la habilidad de las personas.

Adicionalmente se gana un criterio que puede iluminar el accionar de los gobernantes y de los ciudadanos en general: NUNCA AUTORIZAR UNA ACTIVIDAD QUE SÓLO APORTE RENTABILIDAD PRIVADA. EL MÍNIMO ACEPTABLE ES QUE LA RENTABILIDAD PRIVADA SEA IGUAL A LA SOCIAL.

\section{Seguimos teniendo esperanzas}

Ciertamente, cuando observamos la realidad nacional como parte de esa realidad mundial mundializada, pareciera que no es posible tener otras esperanzas que no sean aquellas derivadas de 
la inserción en la globalización, porque el mundo ancho y ajeno es cada vez más ajeno y por eso, más excluyente. En el pasado, a diferencia del presente, nuestra realidad nacional, si bien era parte de la realidad mundial, ésta no estaba mundializada como ahora, aunque ahora tampoco está absolutamente mundializada, o quizá debido a que está mundializada existe una posibilidad real de pensar en saljdas alternativas a la problemática nacional ${ }^{5}$.

Pensamos que, de manera general, la globalización capitalista al mismo tiempo que incluye dentro de sus circuitos una porción importante de la población mundial, también excluye a otro grupo,

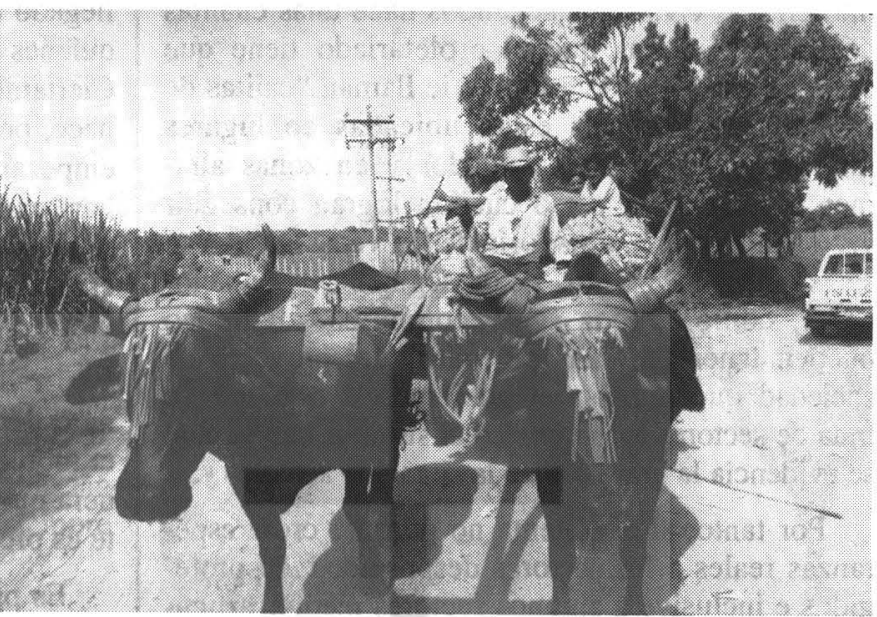
quizá numéricamente más importante que el primero, y este segundo grupo está dividido en dos subgrupos, a saber: los que viven y sufren la exclusión social de forma individual, y quienes enfrentan la exclusión de manera organizada.

Estas dos tendencias: inclusión-exclusión capitalistas son las dominantes a nivel mundial. Hoy en día, los regímenes socialistas han perdido importancia y significación en términos de referencia utópica o paradigmática. Por tal motivo, en nuestro país también es posible detectar esos tres agrupamientos poblacionales $y$, en consecuencia, son observables todas las prácticas socioeconómicas, las medidas políticas y las acciones jurídicas y culturales que posibilitan la reproducción del conjunto social, atendiendo a los intereses del grupo hegemónico, esto es, aquel que representa o sirve a los intereses directos e indirectos del capital nacional y mundial.

Es muy importante tener presente esta situación, a fin de entender los sucesos trascendentales de nuestro acontecer sociopolítico y socioeconómico, como son las medidas propuestas por el gobierno arenero, así como las que pudiera implementar en un futuro; las reacciones de los medios de comunicación masiva, que siguen siendo medios de derecha; los partidos de oposición de derecha y la triste suerte de la izquierda, cuando quiere ser de izquierda, esto es, actuar conforme al interés popular.

Las propuestas del gobiemo cuentan con buena prensa, precisamente porque son medidas que buscan favorecer la buena marcha de esa parte del país que vive y disfruta del sistema. Y precisamente por eso dedicarán todas sus energías a atacar a quienes no las apoyen; se trata de acallar o desprestigiar cualquier posible oposición, aunque al hacerlo se llegue a extremos burdos, como el del editorial de El Diario de Hoy (del 30 de junio de 1999), donde responsabiliza a Marx de los errores del FMLN, cuando lo único que revelan demasiado a menudo las posiciones del FMLN, es su desconocimiento de la teoría marxista, igual o mayor de la que, evidentemente, padece el director del matutino de marras. ¿O será tan sólo mala sangre?

En consecuencia, para las mayorías excluidas no cabe tener esperanzas en el nuevo gobierno. Éste, como otros gobiemos en el pasado, procurará facilitarle las cosas a los privilegiados del siste$\mathrm{ma}$, inclusive, a costa de algunos sectores de las capas medias, para quienes sus condiciones de vida se ven cada vez más deterioradas. Para convencerse de esta realidad, basta con observar donde viven en la actualidad los graduados universitarios y dónde vivían hace 30 sus similares. El deterioro de las condiciones de vida de las capas medias, así como del proletariado, se manifiesta en el

5. Deseamos aclarar que no es una propuesta al estilo de las que elaboran "los consultores", quienes, no por falta de capacidad, nunca proponen nada favorable a las mayorías populares porque éstas no cucntan con dólares para pagarles sus servicios y ellos son de los que: "In gold trust". 
hecho de que los primeros viven en viviendas del tipo en que vivían los segundos hace unas cuantas décadas. Mientras que el proletariado tiene que conformarse con eso a lo que le llaman "cajitas de fósforos", las cuales están ubicadas en lugares muy distantes de San Salvador y en zonas altamente peligrosas, y eso cuando logran conseguir vivienda, porque la mayoría de las veces no logran ser sujetos de crédito. Estos segmentos poblacionales, como grupos socioeconómicos, tampoco pueden tener esperanzas a partir del proyecto de sociedad que impulsa el gobiemo. Y esto que se trata de sectores incorporados al sistema, con lo cual se evidencia la gravedad de la situación actual.

Por tanto, si el sistema no permite crear esperanzas reales a los sectores desposeídos, desprotegidos e inclusive a algunos sectores medios articulados e insuficientemente articulados, es posible pensar que mientras persista el sistema capitalista como única opción importante en el país, las posibilidades de aspirar a mejores condiciones de vida estarán clausuradas y, aún más, se irán estrechando cada vez más, dadas la tendencias que se observan en el presente.

Si no es posible tener esperanzas en el sistema ni en el modelo económico que impulsa el gobierno, ¿eso significa que no hay salidas, que razonablemente las mayorías populares como un todo no pueden tener esperanzas? ¿Que lo más conveniente es buscar la forma de articularse de manera individual en el sistema, gracias a una capacitación excepcional acompañada de un buen padrino, como lo hacen algunos de manera excepcional? Realmente las opciones personales o individuales no resultan ser relevantes; en consecuencia, no hay razón para ocuparse de las mismas. En todo caso se trata de la concepción ideológica neoliberal que potencia y estimula el individualismo, dando por resultado que los más fuertes se impongan sobre los más débiles.

Pero la situación es muy seria en tanto que el sistema tampoco alienta esperanzas de cara a su transformación y, luego del derrumbe de los socialismos reales, algunos antiguos revolucionarios se muestran poco o nada esperanzados en la posibilidad de construir una sociedad socialista, incluso más de alguno se pregunta acerca del para qué.
¿Habrá entonces que aceptar, pues, que hemos llegado al fin de la historia, como les gusta creer a quienes son porque tienen y no porque piensan? Ciertamente, el futuro no se predice sino que se hace, pero para hacerlo es preciso creer, querer $y$ empezar. Si no se cree que es posible, nunca se hará nada. Si no se quiere, de nada servirá creer. Y si no se empieza hoy mismo, por mucho que se crea y se quiera, es posible perderse en el tiempo infinito del mañana que nunca es hoy.

¿Y dónde, entonces, es posible encontrar alguna esperanza? El principio de la solución inicia en el momento en que se formula la pregunta, de manera que ya comenzamos; no obstante, previamente es preciso realizar otras consideraciones.

Es preciso trabajar intensamente a dos niveles: el de la conciencia y el de la práctica. El uno sin el otro no funciona, tienen que ser necesariamente los dos a la vez. El trabajo a nivel de conciencia sin una práctica correspondiente se convierte en retórica o demagogia. Y el trabajo a nivel de la práctica sin su correspondiente nivel de conciencia, se torna en empirismo y puede ser fácilmente manipulado .

La presente situación no sólo es problemática, sino muy propicia para que aflore toda la miseria humana en términos de delincuencia y prostitución; pero lo es también para los oportunistas, así como para los escapistas. El escapismo se presenta en las sociedades cuando éstas experimentan crisis de valores, quiebre de paradigmas, situaciones de postguerra, etc. De allí que no es extraño que aparezcan creyentes de sectas exóticas, "valeverguistas", existencialistas desfasados, etc., con lo cual, cualquier propuesta que se aparte de los cauces "normales" o conocidos es vista de reojo o con desconfianza. Sin embargo, a pesar de todo lo anterior, en lo humano también hay "algo" que nos ha permitido, mal que bien, seguir avanzando, y es por ello, quizá, que los pobres del mundo desde su mundo de desesperanza están generando esperanzas. Ellos están produciendo altemativas reales a su situación de pobreza, las cuales podrían ser de utilidad también para otros sectores afectados por el sistema, cuales son las capas medias empobrecidas y los trabajadores que perciben salarios miserables.

6. Aquiles Montoya, La nueva economía popular: una aproximación empírica, San Salvador: UCA Editores, 1994, contraportada. 
Racionalmente considerada, la fuente de esperanza de los pobres radica en sus propios esfuerzos organizativos, emprendidos con fines económicos y sociales, lo cual caracteriza sus iniciativas como novedosas y de la cual se deriva su potencialidad, a fin de enfrentar la problemática socioeconómica que les aqueja.

Gracias a sus propios proyectos económicos, las comunidades rurales excluidas del sistema están enfrentando de manera eficaz y suficiente sus problemas de pobreza y marginación social; esto es real aquí y en distintos países del tercer mundo. Por ejemplo, la banca popular o banca descalza es ahora todo un paradigma ejemplar del que buscan sacar beneficios, inclusive, aquellos que siempre les negaron financiamiento a los pobres.

Por tanto, es preciso continuar apoyando estos esfuerzos; es preciso seguir ampliando, profundizando y fortaleciendo la organización de los pobres con fines económicos y sociales. Los cultivos orgánicos también son un ejemplo de producción y exportación realizada por los sectores populares organizados.

Es preciso dedicar mayores energías a trabajar con los sectores urbanos, con los llamados informales urbanos. Éstos han demostrado poseer también grandes iniciativas y creatividad para enfrentar los problemas que les han afectado en el pasado, y que ahora se ven profundizados por efecto de la globalización. El comprar barato puede resultar más caro, como ya lo están comprobando en el país cientos de productores de calzado y lo experimentarán en carne propia los demandantes después.

... el libre comercio destruye mayores ingresos de los que se generan derivados de la compra más barata. Efectivamente se compra más barato, pero esta compra lleva a la destrucción de producción que había permitido determinados ingresos. Al destruir esta producción sin sustituirla por nueva y más eficiente se pierde este ingreso sin ninguna contrapartida igual o mayor?.

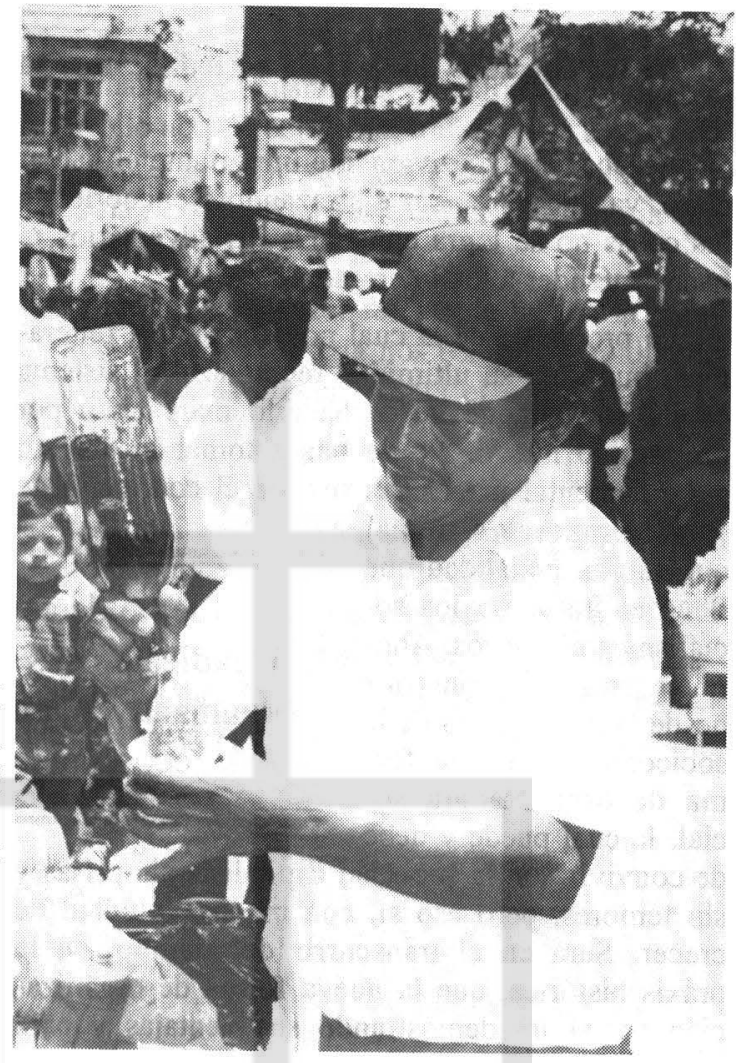

Solamente creciendo en organización, podrá mantenerse la esperanza para los pobres de este mundo. La exclusión que genera la globalización exige y posibilita nuevas formas de organización social diferentes a las sindicales, de manera que es preciso ser innovadores y creativos.

Los nuevos medios electrónicos también pueden ser utilizados por los pobres, de manera que su capacitación en este campo es de suma trascendencia para que puedan crear redes a nivel nacional, regional y mundial, y compartir experiencias con los pobres de otros lugares, como también intercambiar productos. El cibermercado está disponible para ser usado por quienes tienen capacidad, creatividad y necesidad de hacerlo ${ }^{y}$.

7. F.J. Hinkelammert, "El huracán de la globalización:...", Revista Economía Informa, Facultad de Economía, UNAM, marzo, 1997.

8. Si tiene interés en conocer más sobre esta temática, le sugerimos leer los trabajos de Aquiles Montoya: Nueva economía popular: una aproximación teórica, UCA Editores, 1993; La nueva economía popular: una aproximación empírica, UCA Editores, 1994; Informalidad urbana y nueva economía popular, UCA Editores, 1995; “ ¿Es posible abatir la pobreza en el capitalismo?", Revista ECA, enero-febrero, 1998; "El desarrollo económico comunitario. Diagnóstico socio-económico de cien comunidades", revista ECA, mayo-junio, 1999. 


\section{De las entrañas de la vieja sociedad, nace la nueva}

A veces es excesivamente importante el hablar claro, ya que por andar disfrazando o encubriendo las cosas no se logra engañar a los adversarios ni hacer entender a los interesados.

La propuesta de la cual nos ocupamos, reiteramos, busca en su ultimidad reemplazar al sistema capitalista, aunque busca hacerlo marchando por un camino nuevo. No se busca tomar el aparato gubernamental para hacer uso de él con el fin de transformar el sistema, que fue la modalidad que llevó al fracaso a los socialismos históricos. Ahora se trata de construir desde la base misma de la sociedad una nueva forma de organización social, la cual puede y debe

\section{... la fuente de esperanza de los pobres radica en sus propios esfuerzos organizativos, emprendidos con fines económicos y sociales,...}

burguesía; si para conseguir ambos propósitos es preciso, a veces, derramar algunas migajas, pues se hace. Pero no hay que engañarse, las cosas son así. $\mathrm{Y}$ es mejor aceptarlas y buscar nuevos derroteros.

Es obvio que una nueva forma de organización social no caerá del cielo, como tampoco es posible construirla de la nada. La nueva sociedad a la que aspiramos todos aquellos que no compartimos la racionalidad ni el fundamento ni las consecuencias de la organización social capitalista, ya está germinando, y es cuestión de tiempo y de alimentación el que nazca fuerte, sana y bella.

Por tal razón es que, apartando los sectarismos políticos e ideológicos, procuremos articular una sola estrategia popular, síntesis de las diferentes estrategias existentes, a fin de enfrentar los múltiples de convivir con la sociedad capitalista sin prisas y sin temores, pero eso sí, con mucha voluntad de crecer. Será en el transcurrir del tiempo, en la práxis histórica, que la nueva forma de organización social irá demostrando sus ventajas y para quienes es ventajosa. Ello permitirá ir incorporando al proyecto popular a más y más sectores organizados de la población, que rechacen el capitalismo y opten por la nueva organización social.

El poder político no se desprecia, pero tampoco se considera un fin. En una primera fase se requiere de controlar el poder local, porque es a nivel de la localidad que se está construyendo la alternativa popular, y si el poder político no ayuda, al menos que no moleste o interrumpa los procesos.

Algunos timoratos pensarán que al expresar abiertamente que los esfuerzos populares buscan crear una nueva organización social, se está alertando "al enemigo" y éste, que por ahora controla el gobierno central y muchísimos gobiernos locales, excluirá de las ayudas a los gobiemos locales controlados por los sectores populares y bloqueará las iniciativas populares en las zonas controladas por ellos. A lo cual respondemos: eso ya está ocurriendo. Y sucede, precisamente, porque ningún gobiemo de la burguesía gobernará en beneficio de los sectores populares. Su mayor preocupación es asegurar la reproducción del sistema capitalista y su principal compromiso es con la sistema y convivir con sus varias "tentaciones".

Es preciso confrontar los valores propios del sistema capitalista: individualismo, egoísmo, arribismo, derroche, consumismo, etc. con los valores que animan y orientan a las comunidades organizadas: unidad, solidaridad, cooperación, austeridad, trabajo, creatividad, celebración, etc. Tal confrontación debe hacerse, día con día, en la práctica diaria, de manera tal que se haga evidente la superioridad cultural, de una y otra forma de organización social, de cara a enfrentar los problemas de los pobres y excluidos.

Es obvio que si los pobres ven que sus condiciones de vida van mejorando gracias a la organización, la cooperación, la unidad, etc., rechazarán las prácticas de consumo y de vida que exige el sistema y reforzarán sus propios valores. Los sectores organizados comprenderán, a través de su práctica, que el demandar y consumir productos y servicios provenientes de otros sectores organizados es de su interés y de su propio beneficio, porque al hacerlo están posibilitando que los otros demanden y consuman aquello que ellos producen. $\mathrm{Y}$ al proceder de esta manera se conservan los empleos y los ingresos de todos los integrantes de los diferentes sectores, lo cual posibilita que sus economías se mantengan y amplíen, dando lugar a la incorporación de más personas. problemas que significa vivir en las entrañas del 
La práctica también llevará al convencimiento de que todo ahorro individual que se haga en el sector popular significará una ganancia social para el mismo, y que todo derroche individual se traducirá en una pérdida social, lo cual les animará a vivir en austeridad, ya que al hacerlo se posibilita la vida para todos.

Si bien lo anterior está referido al campo del consumo, también se aplica - y con mayor razóna la producción y al uso de los recursos naturales. Es preciso aprender de la relación de los aborígenes con la naturaleza, ya que ellos sin tanto alboroto han demostrado prácticas de producción y de consumo, prácticas de vida sostenibles o sustentables, antes y después del advenimiento del capitalismo.

Por otra parte, debería estar claro que para los pobres, cuya forma de vida se caracteriza por las carencias y la insatisfacción de necesidades reales e imaginarias, se vuelve mucho más fácil e, inclusive, más comprensible el procurar un estilo de desarrollo acorde con la naturaleza y no a costa de ésta, tal como lo ha sido el modelo de producción industrial, consumista y despilfarrador dominante durante los últimos dos siglos.

...consumamos razonablemente lo que la naturaleza y la tecnología nos ofrecen, impidiendo a la segunda atentar contra el equilibrio de la primera .

Pues bien, el escribir sobre esta temática siempre resultará insuficiente, sin importar que se diga lo que se diga; de allí que preferimos dejar este ensayo dentro de los marcos de la brevedad que exige la ensayística, con la muy seria "amenaza" de volver sobre lo mismo, en un futuro no lejano, si es que nos lo permiten quienes pueden hacerlo.

9. Guy Bajoit, "Hipótesis generales sobre el cambio del modelo cultural". Materiales del Instituto Universitario de Desarrollo y Cooperación, Universidad Complutense de Madrid. 